\title{
Geld für Versuchspersonen?
}

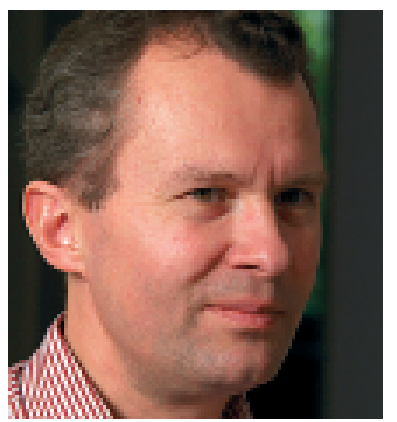

* Prof. Dr. phil., dipl. biol. Christoph Rehmann-Sutter leitet die Arbeitsstelle für Ethik in den Biowissenschaften der Universität Basel, ist Präsident der Nationalen Ethikkommission und Mitglied der Redaktion Ethik der Schweizerischen Ärztezeitung.
Der besonders schockierende Fall der am 13. März 2006 fehlgeschlagenen Studie im Londonder Northwick Park Hospital muss für die Ethik der Forschung am Menschen ein Bündel von Fragen neu aufwerfen. 8 Männer wurden als Freiwillige in die plazebokontrollierte Phase1-Studie des Wirkstoffes TGN1412 einbezogen, die erste Anwendung an Menschen. 6 der 8 Freiwilligen bekamen verum: einen monoklonalen Antikörper, dessen Wirkung darin bestehen sollte, T-Zellen des Immunsystems stark zu aktivieren, damit sie B-Zellen angreifen. Mit dieser Strategie sollten Krankheiten wie die chronische lymphatische Leukämie (B-CLL) oder Autoimmunkrankheiten wie rheumatoide Arthritis und MS behandelt werden können. Innert Minuten nach Verabreichung kämpften die Männer um ihr Leben, fielen ins Koma, erwachten wieder und schrien vor Schmerzen, erbrachen, litten unter Organversagen. Ihre Köpfe schwollen auf die doppelte Grösse an. Ihr Leben konnte dank Intensivbehandlung zwar gerettet werden, sie leiden aber unter bleibenden Schäden, bei einem Patienten sind es Verstümmelungen der Hände und Füsse.

Es kann doch nicht sein, dass hier keine Fehler gemacht worden sind, wie es die Medicine and Healthcare Products Regulatory Agency am 5. April in einem Interimreport vermeldete. Aber wo liegt er? Die Untersuchungen zu dieser sicher komplexen Frage laufen, und ich will ihrem Ergebnis nicht vorgreifen. Ein Punkt aber, der schon unmittelbar nach dem Zwischenfall diskutiert wurde, ist auch für die Schweiz von Belang: Er betrifft die zweitausend Pfund Sterling, die den Versuchspersonen als Entschädigung angeboten wurden. Die Öffentlichkeit wurde sehr schnell mit der beunruhigenden Selbstverständlichkeit konfrontiert, dass die Versuchspersonen sich nämlich vermutlich vor allem - oder sogar ausschliesslich - wegen dieses Lohnes an der Studie beteiligt haben. Robin McKie und Jo Revill zitierten dann in ihrem ausführlichen Fallbericht (The Guardian, 19. März 2006) Medizinethiker, welche die Bezahlung der Freiwilligen in Phase1-Studien, zumindest in dieser Höhe, in Frage stellten. Es habe sich eher um einen Anreiz als um eine Kompensation für die aufgewendete Zeit gehandelt (Janet Derbyshire). Wenn Geld in dieser Höhe angeboten werde, würden die jun- gen Menschen in der Aufklärung die Angaben zu den Risiken einfach überlesen, nur damit sie an das Geld kommen, um die Kredite für ihr Studium zurückzubezahlen (Ray Noble).

Das ist zweifellos richtig, kann mich aber überhaupt nicht beruhigen. Auch in der Schweiz sind Entschädigungen in ähnlicher Höhe üblich und werden in Inseraten, in denen Freiwillige angeworben werden, offen bekanntgegeben. Ich kann mir nicht gut vorstellen, dass Freiwillige für die Teilnahme an Phase-1-Studien andere Motive haben sollten. Sollen im profitorientierten System der pharmazeutischen Industrie ausgerechnet diejenigen, die Risiken persönlich auf sich nehmen, uneigennützig handeln?

Das Ideal der selbstlosen, sich mit den Studienzielen identifizierenden, «autonomen» Versuchsperson, die die drohenden Risiken im vollen Wissen in Kauf nimmt und die Studie mit ihrer Zustimmung rechtfertigt, will mir nicht einleuchten. Damit ist die Verantwortungsfrage nicht abgehakt. Wenn man weniger bezahlt hätte, hätte das ja am Versuch selbst nichts geändert. Es wären nur andere Menschen betroffen gewesen, ärmere vielleicht, denen bereits eine kleinere Entschädigung «genügt» hätte. «Viel» ist ja immer relativ. Mit den zweitausend Pfund hätte man einen Bankdirektor kaum zur unüberlegten Zustimmung verleiten können. Zweitens sind selbst die Uneigennützigen unter den Probanden nicht in der Lage, die Tragweite der Risiken so zu ermessen, dass sie eine Entscheidung treffen könnten, welche die Risiken rechtfertigt. Wenn sie gewusst hätten, dass ihnen dieses Schicksal bevorsteht, hätten sie zu dieser Studie sicher nicht ja gesagt. Aber so stand es nicht in den Unterlagen. Konnte es gar nicht stehen. Die informierte Zustimmung ist eine notwendige Bedingung, keine Rechtfertigung.

Es führt in meinen Augen kein Weg daran vorbei, dass die Aufgabe, die Probanden zu schützen, den Firmen, den Forschern und den Aufsichtsbehörden obliegt, nicht den Versuchspersonen. Man muss damit rechnen, dass letztere es wegen des Geldes tun. So ist das System. Don't blame the victims.

Christoph Rehmann-Sutter * 